\title{
TOTAL INTRAVENOUS ANAESTHESIA (TIVA) WITH DEXMEDETOMIDINE VERSUS NALBUPHINE IN COMBINATION WITH PROPOFOL IN UPPER LIMB ORTHOPAEDIC CLOSED MANIPULATION PROCEDURE- A COMPARATIVE STUDY IN A TERSIARY HEALTH CARE CENTRE IN TRIPURA
}

\section{${ }^{1}$ Dr Rupamay Das, ${ }^{2}$ Dr Rajeh Choudhori, ${ }^{3}$ Dr Biswajit Sutradhar}

${ }^{1} \mathrm{MD}$ (Anaesthesiology), Department of Anaesthesiology, Agartala Government Medical College \& G.B.P Hospital, Agartala, Tripura.

${ }^{2} \mathrm{MD}$ (Anaesthesiology), Department of Anaesthesiology, Agartala Government Medical College \& G.B.P Hospital, Agartala, Tripura

${ }^{3} \mathrm{MD}$ (Anaesthesiology), Associate Professor, Department of Anaesthesiology, Agartala Government Medical College \& G.B.P Hospital, Agartala, Tripura

Article Info: Received 03 January 22; Accepted 13 February 2022

DOI: https://doi.org/10.32553/ijmbs.v6i2.2431

Corresponding author: Dr Rupamay Das

Conflict of interest: No conflict of interest.

\section{Abstract}

Background: Manipulation under anaesthesia is a closed short non-surgical procedure but it demands a cool and calm patient with immobility and relaxation of body parts, to be manipulated. Thus, the role of anaesthesia is vital for success of the procedure. At the same time, it is a challenge for the anaesthesiologist because immobility requires to be maintained and as these procedures are treated as minor, muscle relaxants and intubation are avoided. Adequate analgesia, rapid and complete recovery and controlled sedation is essential to avoid hospital stay.

Materials and Methods: It was an observational analytical study with longitudinal design. This study was conducted at AGMC \& GBP hospital, Tripura and the duration was one and half year. Patient of sex, normal BMI and age between 20-60 years are served as study population. 60 cases are divided into two groups and coded as group D \& N. Intra-procedural hemodynamic (MAP, HR, RR, SPO2), operation time, post procedural (up to 2 hour) pain by Wang - Baker faces pain rating scale and post procedural sedation by Ramsey sedation scale are observed and measured and analysed in this study.

Results: Intra-operative MAP and HR were significantly higher in nalbuphine group than Dexmedetomidine group ( $<<0.05$ ). No significant difference was there in RR and SPO2 (intra-operative). Recovery of orientation was significantly lesser in dexmedetomidine group. Post procedural perception of pain was significantly lower in dexmedetomidine group $(\mathrm{P}<0.005)$. Post procedural sedation was lower in Dexmedetomidine group which was statistically significant $(\mathrm{P}<0.005)$.

Conclusion: Dexmedetomidine is superior to nalbuphine in respect of recovery of orientation, pain control after procedure and control of sedation after procedure. Dexmedetomidine is superior to nalbuphine as it provides adequate analgesic and sedation without increasing MAP and HR in the above said procedure.

Keywords: Dexmedetomidine, Nalbuphine, MAP- Mean arterial pressure, HR- Heart Rate, RR- Respiratory Rate

\section{Introduction}

Manipulation under anaesthesia is a closed short nonsurgical procedure but it demands a cool and calm patient with immobility and relaxation of body part to be manipulated. Thus, the role of anaesthesia is vital for success of the procedure. At the same time, it is a challenge for the anaesthesiologist because immobility requires to be maintained and as these procedures are treated as minor, muscle relaxant and intubation are avoided ${ }^{\mathrm{i}}$. Moreover, adequate analgesia, rapid and complete recovery and controlled sedationis essential to avoid hospital stay ${ }^{\text {ii }}$.
Various studies had concluded that manipulation under anaesthesia was an effective approachto restoring articular and myo-fascial movements. There are also plenty of published articles that indicate effectiveness of MUA particularly for closed upper limb procedures $\mathrm{s}^{\mathrm{iii}}$. There has been search for ideal and appropriate anaesthetic agent for MUA and Total intravenous anaesthesia (TIVA) has come up in that direction.

In the recent years propofol has been tried to achieve TIVA ${ }^{\text {iv }}$. But propofol is unable to provide analgesia. So, propofol is 
used along with opioids like- fentanyl, alfentanyl, ramifentanyl etc. with varying degree of efficacy. But most of these opioids cause respiratory depression. Dexmedetomidine is an alpha agonist having sedative, anxiolytic, hypnotic, analgesic, and sympatholytic properties $^{\mathrm{v}}$. It produces these effects by inhibition of central sympathetic outflow by blocking the alpha receptors in the brainstem, thereby inhibiting the release ofnorepinephrine.

There is evidence that dexmedetomidine decreases postoperative pain, postoperative opioid usage, and nausea. There are no absolute contraindications to the use of dexmedetomidine ${ }^{\text {vi }}$. However, it should be used cautiously in patients with bradycardia and hypotension as the medication may exacerbate these findings. Nalbuphine hydrochloride is an agonist -antagonist opioid, chemically related to oxymorphine and naloxone ${ }^{\text {vii }}$.

Nalbuphine is a kappa-opioid receptor agonist and a partial mu-opioid receptor antagonist. Analgesic properties are mediated through agonist activity at the kappa-opioid receptor $^{\text {viii. }}$. Because of this unique mixed agonistantagonist opioid receptor activity of nalbuphine, it provides analgesia with less nausea, pruritus, and respiratory depression when compared to morphine.

Tripura a small hilly state in the North-East India advancing rapidly in healthcare settings and also in providing better health care day by day. But no study was conducted here to assess the superiority of these two drugs ${ }^{\mathrm{ix}}$. Hence, the present study is designed to compare the efficacy of dexmedetomidine with nalbuphine in combination with propofol in upper limb orthopaedic closed manipulation procedure. Data generated will also provide inputs to the pharmacodynamics profile of the drugs as well as strategy formulation for patient management.

\section{Aim}

The study aims to generating comparison profile regarding the effects of Dexmedetomidine and Nalbuphine in combination with propofol while providing more effective stability of intra procedural hemodynamic and post procedural pain and sedation among the patients underwent upper limb orthopaedic closed manipulation procedure in a tertiary care hospital, Agartala, West Tripura district.

\section{Method and Material}

It was an observational analytical study with longitudinal design conducted in the Department of Anaesthesiology, Agartala Government Medical College and G. B. Pant Hospital, located at the lap of Agartala, the capital of Tripura for one and half year (May2019 - October2020). The patients of both sexes with normal BMI (according to ICMR, BMI for Asian population was $18.5-22.9 \mathrm{~kg} / \mathrm{m}^{2}$ ) of age between 20-60 years undergoing upper limb orthopaedic closed manipulation procedure, were served as study population.

\section{Inclusion criteria:}

- Age- $20-60$ years.

- Either Sex.

- BMI - 18.5-22.9 kg/m²

- ASA physical status - Grade I \& Grade II

\section{Exclusion criteria:}

Patients not willing to be included in the study.

- Severe hypertension.

- Uncontrolled diabetes mellitus.

- Severe hypotension/ shock.

\section{Sample size:}

Sample size: The sample size was decided by the following formula

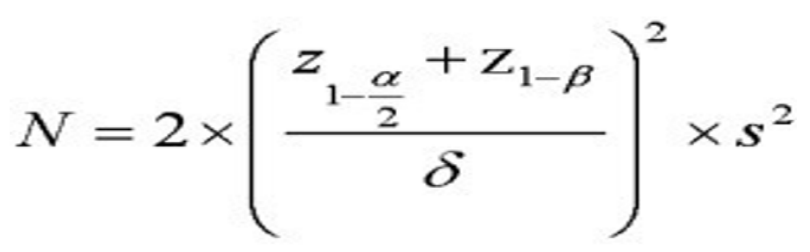

Where, $\mathrm{N}=$ Sample size in one group

$\delta=\mathrm{SD}$ of control group

$\mathrm{S}=$ Pooled Variance

$$
s^{2}=\frac{\left(n_{1}-1\right) s_{1}^{2}+\left(n_{2}-1\right) s_{2}^{2}}{n_{1}+n_{2}-2}
$$

\section{Sampling technique:}

All 60 cases fulfilling inclusion and exclusion criteria were taken up for the study with equal probability of allocation. Allocation Concealment was done by coded opaque sealed envelope. 60 opaque envelops were divided into two halves (each half 30) and coded as D \& N. Then two groups were mess up and patients were allowed to pick any one of them. If the patient picked up D envelop then he/she was in Dexmedetomidine group and vice versa.

\section{Data collection:}

The study was carried out on 60-patients within the age group 20-60 years, either sex of ASAI and II physical status, undergoing upper limb orthopaedic closed manipulation were divided into two groups (group $\mathrm{D}=$ Dexmedetomidine group and group $\mathrm{N}=$ Nalbuphine group) of 30 patients each $(\mathrm{n}=30)$. 
Both the groups were received uniform premedication with injection Ondansetron $8 \mathrm{mg}$ iv and injection Omeprazole $40 \mathrm{mg}$ iv. Group D was received injection Propofol (1\%) $1.5 \mathrm{mg} / \mathrm{kg}$ plus injection Dexmedetomidine $50 \mathrm{mcg}$ iv bolus, while group $\mathrm{N}$ was received injection Propofol (1\%) $1.5 \mathrm{mg} / \mathrm{kg}$ plus injection Nalbuphine $10 \mathrm{mg}$ iv bolus prior to procedure.

\section{Results}

For the study among 60 study subjects $46.7 \%$ belonged to $<30$ years' age group followed by $26.7 \%$ in $30-40$ years' age group and $16.6 \%$ in $41-50$ years' age group. Rest $10 \%$ of the subjects belonged to $>50$ years' age group. Mean age was $33.83 \pm 12.21$ years. For the analysis majority of the study subjects were males $(78.3 \%)$ and rest $21.7 \%$ were females. As per the outcome study age, weight and BMI was compared between the two groups but there was no statistically significant difference found between the two groups in these parameters $(\mathrm{p}>.05)$. The analysis has found that there was no statistically significant difference between the twogroups in distribution MAP, HR and RR during administration of drug; $\mathrm{p}>.05$.

The study has analysed different variable at 5 minutes after administration of both the drugs, MAP and HR were significantly higher in nalbuphine group than dexmedatomedine group $(\mathrm{p}<0.05)$, whereas no significant difference was there in RR among both the groups ( $>>0.05$ ). Apart from this at 10 minutes after administration of both the drugs, MAP and HR were significantly higher in nalbuphine group than dexmedatomedine group $(\mathrm{p}<0.05)$, whereas no significant difference was there in RR among both the groups $(p>0.05)$. Moreover, the outcome of the analysis shows that recovery of orientation after administration of drug was significantly lower in Dexmedetomidine group than Nalbuphine group; $\mathrm{p}<0.05$. Additionally, there was no statistically significant difference between the two groups in distribution of MAP, HR and RR at the time of discharge from hospital; $\mathrm{p}>0.05$.

Table 1: Pain rating and drug

\begin{tabular}{|c|c|c|c|c|}
\hline Drug/ Duration and pain rating & Dexmedetomidine & Nalbuphine & Total & P-value \\
\hline \multicolumn{5}{|l|}{ Immediately } \\
\hline Hurts little bit & $30(100 \%)$ & 0 & $30(100.0 \%)$ & \multirow[b]{2}{*}{0.00} \\
\hline Hurts little more & 0 & $30(100.0 \%)$ & $30(100.0 \%)$ & \\
\hline \multicolumn{5}{|l|}{30 mins } \\
\hline Hurts little bit & $30(100 \%)$ & 0 & $30(100.0 \%)$ & \multirow{2}{*}{0.00} \\
\hline Hurts little more & 0 & $30(100.0 \%)$ & $30(100.0 \%)$ & \\
\hline \multicolumn{5}{|l|}{60 mins } \\
\hline Hurts little bit & $30(100 \%)$ & 0 & $30(100.0 \%)$ & \multirow{2}{*}{0.00} \\
\hline Hurts little more & 0 & $30(100.0 \%)$ & $30(100.0 \%)$ & \\
\hline \multicolumn{5}{|l|}{120 mins } \\
\hline Hurts little bit & $30(100 \%)$ & 0 & $30(100.0 \%)$ & \multirow{2}{*}{0.00} \\
\hline Hurts little more & 0 & $30(100.0 \%)$ & $30(100.0 \%)$ & \\
\hline
\end{tabular}

Above table shows that perception of pain at immediate, 30, 60 and 120 minutes after completion of procedure was lower in Dexmedetomidine group than Nalbuphine and this was statistically significant $(\mathrm{p}<0.05)$. 
Table 2: Comparison of sedation scores

\begin{tabular}{|l|l|l|l|l|}
\hline $\begin{array}{l}\text { Drug/ Duration and Ramsey Sedation } \\
\text { Score }\end{array}$ & Dexmedetomidine & Nalbuphine & Total & P-value \\
\hline Immediately & $30(100 \%)$ & 0 & & \\
\hline Cooperative, oriented, tranquil & 0 & $30(100.0 \%)$ & $30(100.0 \%)$ & 0.00 \\
\hline Responsive to commands only & & & & \\
\hline $\mathbf{3 0}$ mins & $30(100 \%)$ & 0 & $30(100.0 \%)$ & \multirow{2}{*}{0.00} \\
\hline Cooperative, oriented, tranquil & 0 & $30(100.0 \%)$ & $30(100.0 \%)$ & \\
\hline Responsive to commands only & & & $30(100.0 \%)$ & \multirow{2}{*}{0.00} \\
\hline $\mathbf{6 0}$ mins & $30(100 \%)$ & 0 & $30(100.0 \%)$ & \\
\hline Cooperative, oriented, tranquil & 0 & $30(100.0 \%)$ & & \\
\hline Responsive to commands only & & 0 & $30(100.0 \%)$ & \multirow{2}{*}{0.00} \\
\hline $\mathbf{1 2 0}$ mins & $30(100 \%)$ & $30(100.0 \%)$ & $30(100.0 \%)$ & \\
\hline Cooperative, oriented, tranquil & 0 & 0 & & \\
\hline Responsive to commands only & & 0 & & \\
\hline
\end{tabular}

Above table shows that sedation at immediate, 30, 60 and 120 minutes after completion of procedure was less in Dexmedetomidine group than Nalbuphine and this was statistically significant $(\mathrm{p}<0.05)$.

\section{Discussion}

Both the groups were found comparable in respect of demographic profile (Age, Sex) and in respect of anthropometric parameters (Body weight, BMI) as there was no significant statistical difference between the two groups in terms of demographic profile and anthropometric parameters $^{\mathrm{x}}$. It was observed that both the drugs had lowered the MAP after 5 minutes and 10 minutes of administration but none of them caused hypotension. The mean MAP was significantly lower in dexmidatomedine group than nulbuphine group both at $5 \mathrm{~min}$ and $10 \mathrm{~min}$ point of time.

Thus, the present study has shown that there was no significant change in vital parameters like $\mathrm{RR}$ and $\mathrm{SpO} 2$ at any point of time in both the groups. Time taken for recovery of orientation after administration of both the drugs was also measured and compared ${ }^{\mathrm{xi}}$. It was observed that mean time for recovery of orientation after administration of drug was significantly lower in Dexmedetomidine group (10.87 \pm 1.13$)$ than Nalbuphine group (12.83 \pm 1.96$)$.

In the present study post-operative pain and sedation level were measured to compare the effect of both the anaesthetic agents on pain and sedation after operative procedure. Pain was measured using Faces pain rating scale and sedation was measured using Ramsey sedation score at immediately after procedure completion, at $30 \mathrm{~min}, 60 \mathrm{~min}$ and $120 \mathrm{~min}$ after procedure completion. This study has denoted that postoperative pain was lesser after administration of Dexmedetomidine than Nalbuphine at all points of time (immediately after, 30 minutes, 60 minutes and 120 minutes post-operative) which was statistically significant also.

Similarly, in the study it was observed that post-operative sedation was lesser after administration of Dexmedetomidine than Nalbuphine at all points of time (immediately after, 30 mins, 60 mins and 120 mins post-operative) which was also statistically significant ${ }^{\mathrm{xii}}$.

\section{Conclusion}

Dexmedetomidine is superior to Nalbuphine in respect of recovery of orientation after administration of drug. Apart from this, Dexmedetomidine is superior to Nalbuphine in respect of pain control after the procedure. Dexmedetomidine is superior to Nalbuphine in respect of control of sedation after the procedure. Moreover, Dexmedetomidine is superior to Nalbuphine as it provides adequate analgesia and sedation without increasing mean arterial pressure (MAP) and heart rate (HR) in the above said procedure. 
1. 'Palmieri NF. Smoyak S. Chronic low back pain: a study of the effects of manipulation under anesthesia. Journal of Manipulative \& Physiological Therapeutics. 25(8):E8- E17, October 2002.

2. ii Feuerstein C, Weil Jr. L, Weil Sr. L, Joint Manipulation Under Anesthesia for Arthrofibrosis After Hallux Valgus Surgery. The Journal of Foot \& Ankle Surgery 2016; 55:7680.

3. iii Bidwai AS, Mayne A, Nielsen M, et al. Limited capsular release and controlled manipulation under anaesthesia for the treatment of frozen shoulder. Shoulder and Elbow. January 1, 2016;8(1) 9-13.

4. iv Mun S and Baek C. Clinical efficacy of hydrodistention with joint manipulation under interscalene block compared with intraarticular corticosteroid injection for frozen shoulder: a prospective randomized controlled study. J Shoulder Elbow Surg (2016) 25, 1937-1943.

5. $v$ The post operative adverse effects of inhalational anesthetics. Boucher BA, Witt WO, Foster TS. Heart Lung.1986;15(1):63-9.

6. vi Total Intravenous Anesthesia. Gillies. M.A.M European Journal of Anaesthesiology: 2003; 20(12):993.

7. vii Opioid Induced respiratory depression: A Mathematical model for fentanyl. Magosso $E$, Ursino M, van Oostrom JH. IEEE Trans Biomed Eng. 2004;51(7):1115-28.
8. viii Andersen JH, Grevstad U, Siegel H, Dahl JB, Mathiesen $\mathrm{O}$, Jæger P. Does Dexmedetomidine Have a Perineural Mechanism of Action When Used as an Adjuvant to Ropivacaine?: A Paired, Blinded, Randomized Trial in Healthy Volunteers. Anesthesiology. 2017 Jan;126(1):66-73.

9. ix Blaudszun $\mathrm{G}$, Lysakowski $\mathrm{C}$, Elia N, Tramèr MR. Effect of perioperative systemic $\alpha 2$ agonists on postoperative morphine consumption and pain intensity: systematic review and meta-analysis of randomized controlled trials. Anesthesiology. 2012 Jun;116(6):1312-22.

10. ' Baxter AD, Samson B, Penning J, Doran R, Dube LM. Prevention of epidural morphineinduced respiratory depression with intravenous nalbuphine infusion in postthoracotomy patients. Can J Anaesth. 1989 Sep;36(5):503-9.

11. ${ }^{\mathrm{xi}}$ Wong-Baker FACES Pain Rating Scale.

Available from https://wongbakerfaces.org/wpcontent/uploads/ 2016/05/FACES_English_Blue_winstructions.pdf. [Last assessed on 28th Jan, 2022]

12. xii Sedation scales. Available from https:// www. aic. cuhk. edu.hk /web8/ sedation\% 20scale.htm [Last assessed on 28th Jan, 2022] 